\title{
Case Report \\ Cardiac Failure as an Unusual Presentation in a Patient with History of Amyotrophic Lateral Sclerosis
}

\author{
Mohammad Hasan Namazi, ${ }^{1}$ Isa Khaheshi, ${ }^{1}$ Habib Haybar, ${ }^{2}$ and Shooka Esmaeeli ${ }^{3}$ \\ ${ }^{1}$ Cardiovascular Research Center, Modarres Hospital, Shahid Beheshti University of Medical Sciences, Tehran, Iran \\ ${ }^{2}$ Cardiovascular Research Center, Ahvaz Jundishapur University of Medical Sciences, Ahvaz, Iran \\ ${ }^{3}$ Students Scientific Research Center (SSRC), Tehran University of Medical Sciences (TUMS), Tehran, Iran \\ Correspondence should be addressed to Isa Khaheshi; isa_khaheshi@yahoo.com
}

Received 9 March 2014; Revised 24 May 2014; Accepted 20 June 2014; Published 15 July 2014

Academic Editor: Dominic B. Fee

Copyright (C) 2014 Mohammad Hasan Namazi et al. This is an open access article distributed under the Creative Commons Attribution License, which permits unrestricted use, distribution, and reproduction in any medium, provided the original work is properly cited.

\begin{abstract}
Amyotrophic lateral sclerosis (ALS) is the most well-known form of motor neuron diseases in which both upper and lower motor neurons are involved in this disease. We presented an unusual case of ALS whom had presented with chief complaint of dyspnea. Cardiac failure was diagnosed at the final stage of the ALS disease. The pathogenetic mechanism leading to an elevated occurrence of cardiomyopathy in ALS is not comprehensible. Dilated cardiomyopathy has been explained in some previous studies. Based on the collected data, it was hypothesized that cardiomyopathy is underdiagnosed in the ALS population, probably because symptoms are masqueraded as a result of the patients' disability. It was suggested that in all motor neuron diseases a serial cardiological evaluation should be executed, including annual echocardiography.
\end{abstract}

\section{Introduction}

Amyotrophic lateral sclerosis (ALS) is the most well-known form of motor neuron diseases in which both upper and lower motor neuron are involved in it. We presented an unusual case of ALS that presented with the chief complaint of dyspnea. Cardiac failure was diagnosed at the final stage of the ALS disease $[1,2]$. Cardiac involvement has been rarely illustrated as part of the motor neuron diseases among literature [3].

Dilated cardiomyopathy has been explained in some previous studies [3]. Based on the collected data, it was hypothesized that cardiomyopathy is underdiagnosed in the ALS population, probably because symptoms are masqueraded as a result of the patients' disability. It is suggested that in all motor neuron diseases a serial cardiologic evaluation should be executed, including annual echocardiography.

\section{Case Presentation}

A 72-year-old man with history of amyotrophic lateral sclerosis (ALS) from 3 years ago presented in the emergency unit with complaint of dyspnea exacerbation from New York Heart Association (NYHA) functional class II to IV, orthopnea, and paroxysmal nocturnal dyspnea from 6 weeks before presentation. He had a history of stent angioplasty on LAD and RCA which was performed for him 4 years ago. His echocardiography findings after stent angioplasty revealed ejection fraction of $50 \%$. After that, he was in stable condition, until progressive weakness and atrophy of left upper limb started and involved right upper limb and then lower limbs gradually, and diagnosis of ALS was established due to clinical presentation, electromyography (EMG) findings, and ruling out of the other similar motor neuron disease. Riluzole was prescribed for him but it was not tolerated due to significant side effects including nausea, headache, and dizziness. Recently, he has had dysphagia to liquids.

On physical examination, blood pressure was $105 / 70 \mathrm{mmHg}$, heart rate was $92 / \mathrm{min}$, respiratory rate was 20 , and body temperature was $36.9^{\circ} \mathrm{C}$. On chest auscultation, there were fine rales on the base of both lung fields, and grade II systolic murmur on apex and left sternal border were heard. 
TABLE 1: Comparison of current echo parameters of the patient with 3-year-earlier echo findings.

\begin{tabular}{|c|c|c|}
\hline \multirow[b]{2}{*}{ Echo parameters } & \multicolumn{2}{|c|}{ Time } \\
\hline & $\begin{array}{l}\text { 3-year-earlier } \\
\text { echo findings }\end{array}$ & $\begin{array}{c}\text { Current } \\
\text { echo findings }\end{array}$ \\
\hline End-diastolic diameter & $52.0 \mathrm{~mm}$ & $66.0 \mathrm{~mm}$ \\
\hline End-systolic diameter & $37.0 \mathrm{~mm}$ & $58.0 \mathrm{~mm}$ \\
\hline Septal wall thickness & $9.0 \mathrm{~mm}$ & $10.0 \mathrm{~mm}$ \\
\hline Lateral wall thickness & $9.5 \mathrm{~mm}$ & $10.0 \mathrm{~mm}$ \\
\hline Ejection fraction & $50 \%$ & $20 \%$ \\
\hline Left atrium area & $17.5 \mathrm{~cm}^{2}$ & $32 \mathrm{~cm}^{2}$ \\
\hline Valvular abnormalities & $\begin{array}{c}\text { Trivial MR, } \\
\text { trivial TR }\end{array}$ & $\begin{array}{c}\text { Moderate MR, } \\
\text { mild TR }\end{array}$ \\
\hline Diastolic dysfunction & Mild & Severe \\
\hline
\end{tabular}

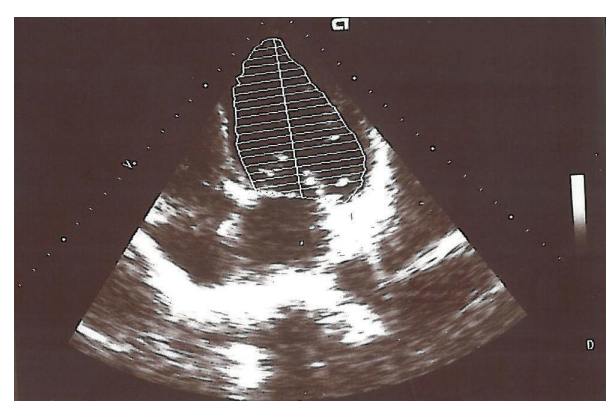

FIgURE 1: Transthoracic echocardiography revealed global hypokinesia of the LV with left ventricular ejection fraction (EF) of $20 \%$ which was measured by biplane Simpson method. The three-yearearlier echocardiography had showed ejection fraction of $50 \%$.

The new echocardiography was done for him which showed ejection fraction of $20 \%$ with global hypokinesia (Figure 1 and Table 1); myocardial perfusion scan was normal which is highly predictive for the absence of CAD in the setting of heart failure and left ventricular dysfunction. He had no history of recent viral or bacterial infections. Serial ECGs showed no significant ST-T changes.

Complete blood count, blood urea nitrogen (BUN), serum creatinine, blood glucose, $\mathrm{Na}^{+}, \mathrm{K}^{+}$, SGOT, SGPT, alkaline phosphatase, bilirubin, T3, T4, TSH, CK-MB, and serial cardiac troponin I were all within normal ranges.

Treatment commenced with administration of furosemide, captopril, digitalis, and spironolactone.

After two days of his admission, he had an episode of bradycardia and respiratory apnea and was intubated due to low oxygen saturation and high $\mathrm{Pa} \mathrm{CO}_{2}$ level.

The patient was intubated for 7 days without significant improvement in his condition, and in the 9th hospital day his blood pressure was not detected and cardiac rhythm became asystole; regardless of cardiopulmonary resuscitation for sixty minutes he remained pulseless and finally expired.

\section{Discussion}

Amyotrophic lateral sclerosis is the most well-known form of motor neuron diseases. ALS occurs in 1 to 2 people per
100,000 . We presented an unusual case of amyotrophic lateral sclerosis that presented with cardiac failure at the final stage of the disease $[1,2]$.

Cardiac involvement has been rarely illustrated as part of the motor neuron diseases. Cardiac denervation related to involvement of the sympathetic nervous system has been depicted in patients in the early stages of ALS [3].

The current patient was not contented to undergo coronary angiography. So, due to high negative predictive value of myocardial perfusion scan for the absence of CAD in the setting of heart failure and left ventricular dysfunction, this noninvasive imaging modality was done for him [4].

The pathogenetic mechanism leading to an elevated occurrence of cardiomyopathy in ALS is not comprehensible. Dilated cardiomyopathy has been explained in some previous studies. Based on the collected data, it was hypothesized that cardiomyopathy is underdiagnosed in the ALS population, probably because symptoms are masqueraded as a result of the patients' disability. It was suggested that in all motor neuron diseases a serial cardiological evaluation should be executed, including annual echocardiography [5-7].

Moreover, the clinical impact of autonomic nervous dysfunction in ALS is vague in early stage but significant in the end stage of the disease, when ventilators are needed. Further studies may be required to show the pathognomonic importance of autonomic dysfunction in ALS [8].

\section{Conflict of Interests}

The authors declare that there is no conflict of interests regarding the publication of this paper.

\section{References}

[1] P. M. Worms, "The epidemiology of motor neuron diseases: a review of recent studies," Journal of the Neurological Sciences, vol. 191, no. 1-2, pp. 3-9, 2001.

[2] G. Logroscino, B. J. Traynor, O. Hardiman et al., "Incidence of amyotrophic lateral sclerosis in Europe," Journal of Neurology, Neurosurgery and Psychiatry, vol. 81, no. 4, pp. 385-390, 2010.

[3] P. L. Oey, P. E. Vos, G. H. Wieneke, J. H. J. Wokke, P. J. Blankestijn, and J. M. Karemaker, "Subtle involvement of the sympathetic nervous system in amyotrophic lateral sclerosis," Muscle \& Nerve, vol. 25, no. 3, pp. 402-408, 2002.

[4] J. E. Udelson, C. D. Shafer, and I. Carrió, "Radionuclide imaging in heart failure: assesing etiology and outcomes and implications for management," Journal of Nuclear Cardiology, vol. 9, no. 5, pp. S40-S52, 2002.

[5] H. J. Gdynia, A. Kurt, S. Endruhn, A. C. Ludolph, and A. D. Sperfeld, "Cardiomyopathy in motor neuron diseases," Journal of Neurology, Neurosurgery and Psychiatry, vol. 77, no. 5, pp. 671673, 2006.

[6] G. W. Dec and V. Fuster, "Idiopathic dilated cardiomyopathy," The New England Journal of Medicine, vol. 331, no. 23, pp. 1564$1575,1994$.

[7] N. Takayama, Y. Iwase, S. Ohtsu, and H. Sakio, “'Takotsubo” cardiomyopathy developed in the postoperative period in 
a patient with amyotrophic lateral sclerosis," Japanese Journal of Anesthesiology, vol. 53, no. 4, pp. 403-406, 2004.

[8] T. Shimizu, "Sympathetic hyperactivity and sympathovagal imbalance in amyotrophic lateral sclerosis," European Neurological Review, vol. 8, no. 1, pp. 46-50, 2013. 


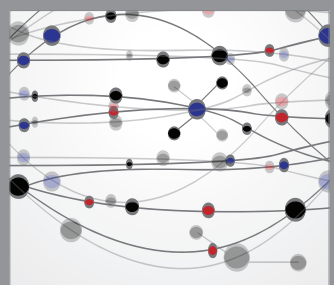

The Scientific World Journal
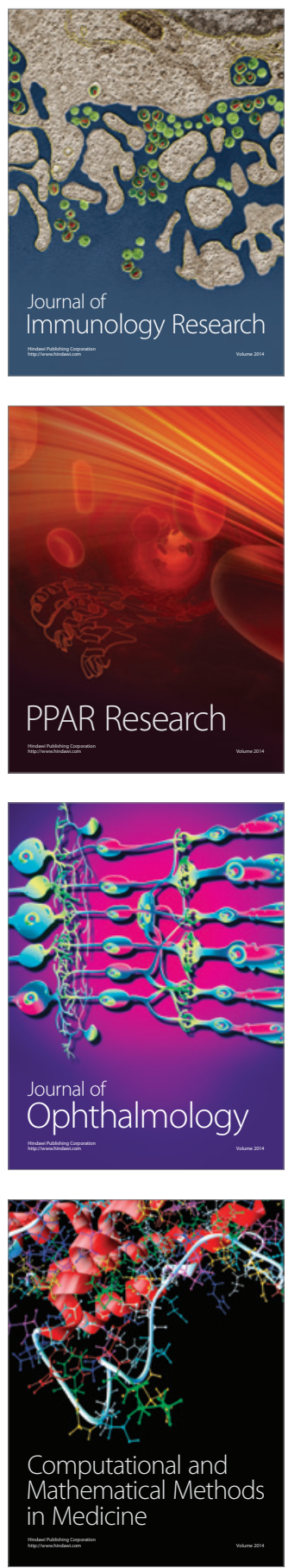

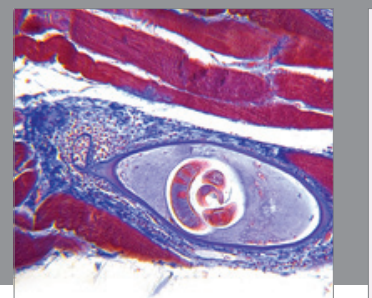

Gastroenterology

Research and Practice
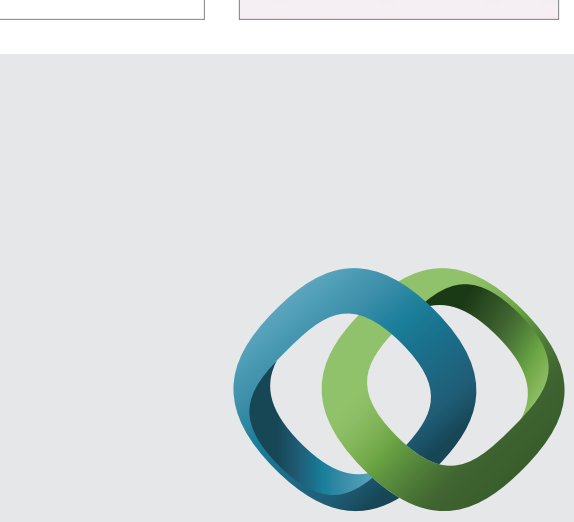

\section{Hindawi}

Submit your manuscripts at

http://www.hindawi.com
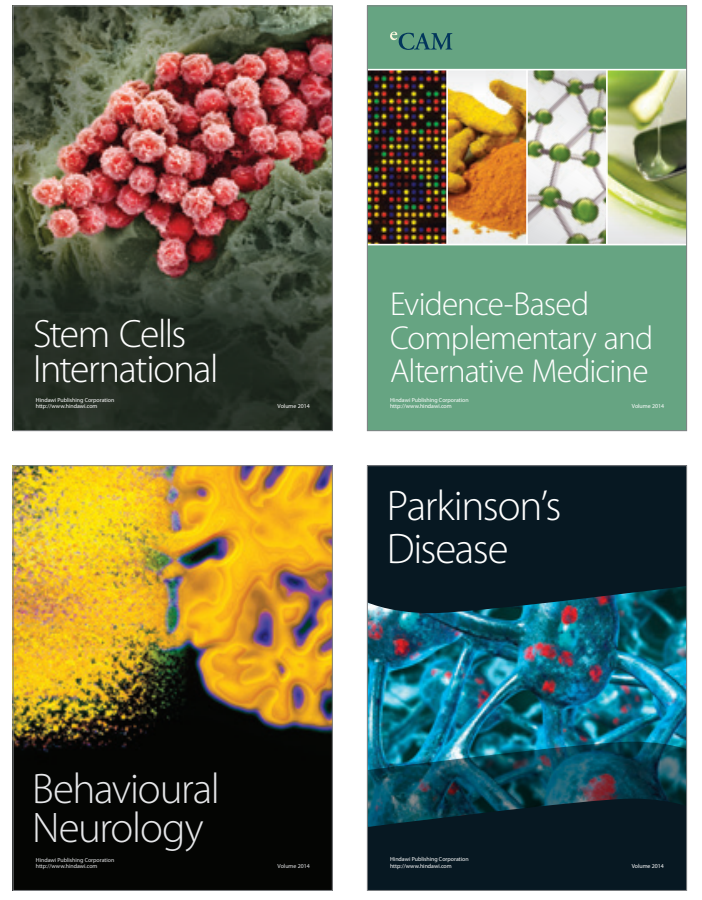
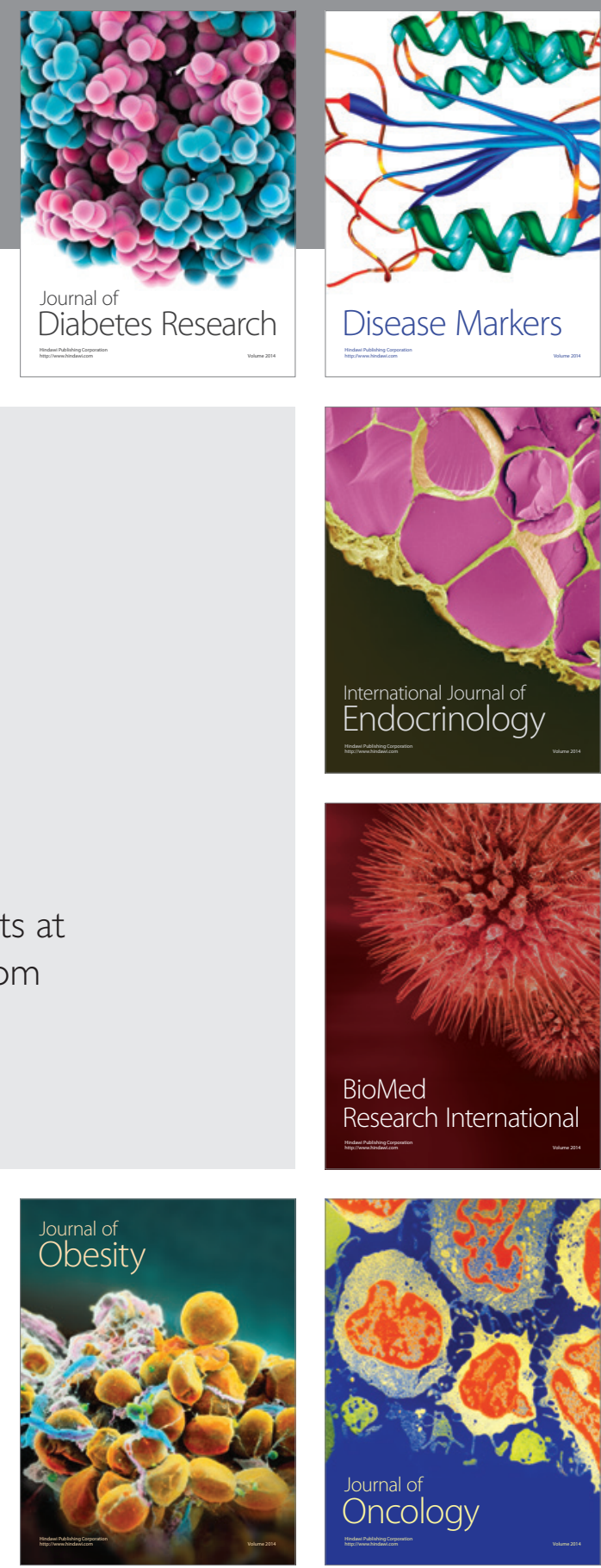

Disease Markers
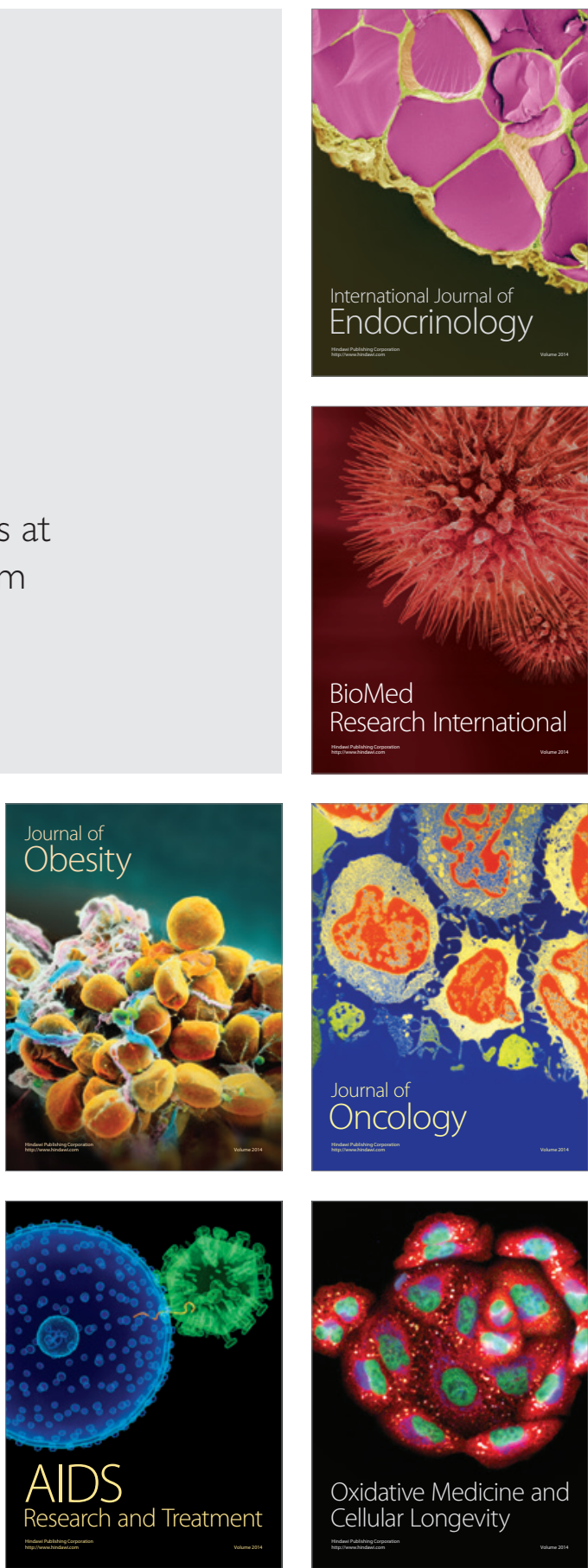